\title{
Rationale and Design of a Statewide Cohort to examine efficient resource utilization for patients with Intracerebral hemorrhage (EnRICH)
}

Farhaan S. Vahidy ${ }^{1 *}$, Ellie G. Meyer ${ }^{1}$, Arvind B. Bambhroliya' ${ }^{1}$, Jennifer R. Meeks ${ }^{1}$, Charles E. Begley ${ }^{2}$, Tzu-Ching Wu', Jon E. Tyson ${ }^{3}$, Charles C. Miller ${ }^{3}$, Ritvij Bowry ${ }^{4}$, Wamda O. Ahmed ${ }^{4}$, Gretchel A. Gealogo ${ }^{5}$, Louise D. McCullough', Steven Warach ${ }^{5}$ and Sean I. Savitz ${ }^{1}$

\begin{abstract}
Background: Intracerebral hemorrhage is a devastating disease with no specific treatment modalities. A significant proportion of patients with intracerebral hemorrhage are transferred to large stroke treatment centers, such as Comprehensive Stroke Centers, because of perceived need for higher level of care. However, evidence of improvement in patient-centered outcomes for these patients treated at larger stroke treatment centers as compared to community hospitals is lacking.

Methods / design: "Efficient Resource Utilization for Patients with Intracerebral Hemorrhage (EnRICH)" is a prospective, multisite, state-wide, cohort study designed to assess the impact of level of care on long-term patient-centered outcomes for patients with primary / non-traumatic intracerebral hemorrhage. The study is funded by the Texas state legislature via the Lone Star Stroke Research Consortium. It is being implemented via major hub hospitals in large metropolitan cities across the state of Texas. Each hub has an extensive network of "spoke" hospitals, which are connected to the hub via traditional clinical and administrative arrangements, or by telemedicine technologies. This infrastructure provides a unique opportunity to track outcomes for intracerebral hemorrhage patients managed across a health system at various levels of care. Eligible patients are enrolled during hospitalization and are followed for functional, quality of life, cognitive, resource utilization, and dependency outcomes at 30 and 90 days post discharge. As a secondary aim, an economic analysis of the incremental cost-effectiveness of treating intracerebral hemorrhage patients at higher levels of care will be conducted.

Discussion: Findings from EnRICH will provide much needed evidence of the effectiveness and efficiency of regionalized care for intracerebral hemorrhage patients. Such evidence is required to inform policy and streamline clinical decision-making.
\end{abstract}

Keywords: Stroke, Intracerebral hemorrhage, Patient-centered outcomes, Quality of life, Readmission rate, Mortality, Cost effectiveness, Resource utilization

\footnotetext{
* Correspondence: Farhaan.Vahidy@uth.tmc.edu

'Department of Neurology and the Institute for Stroke and Cerebrovascular Disease, McGovern Medical School, University of Texas - Health, Houston, TX, USA

Full list of author information is available at the end of the article
}

(c) The Author(s). 2018 Open Access This article is distributed under the terms of the Creative Commons Attribution 4.0 International License (http://creativecommons.org/licenses/by/4.0/), which permits unrestricted use, distribution, and reproduction in any medium, provided you give appropriate credit to the original author(s) and the source, provide a link to the Creative Commons license, and indicate if changes were made. The Creative Commons Public Domain Dedication waiver (http://creativecommons.org/publicdomain/zero/1.0/) applies to the data made available in this article, unless otherwise stated. 


\section{Background Introduction}

Intracerebral Hemorrhage $(\mathrm{ICH})$ is a devastating disease. Although $\mathrm{ICH}$ accounts for about $10-15 \%$ of all stroke subtypes in the United States (US), this proportion is reported to be as high as 50\% in certain regions of the world [1]. The burden of disease imposed by $\mathrm{ICH}$ is tremendous. Approximately $50 \%$ of $\mathrm{ICH}$ patients do not survive beyond 30 days, and up to $80 \%$ fail to achieve functional independence $[2,3]$. Furthermore, approximately $90 \%$ of $\mathrm{ICH}$ patients report their quality of life (QOL) to be below average, including 20\% stating their QOL to be worse than death [4]. There are no class I evidence-based modalities that improve $\mathrm{ICH}$ outcomes. The mainstay of management revolves around hemodynamic stabilization, neurological monitoring, blood pressure titration, reversal of coagulopathy (if indicated), surgical interventions (in selected patients), secondary stroke prevention, and rehabilitation [5]. It has also been reported that the majority of hospitals do not have well-developed ICH management protocols [6]. Clinical trials for early blood pressure management and surgical interventions in $\mathrm{ICH}$ patients have demonstrated safety with limited and equivocal efficacy $[7,8]$.

There are national and regional data showing that a large number of $\mathrm{ICH}$ patients are transferred from smaller community hospitals to bigger stroke treatment centers, probably for a perceived need of higher level of care (HLOC) [9, 10]. Data also suggest that the proportion of transferred patients to large hospitals has been increasing periodically [10]. However, the impact of management of ICH patients at a certain level of care on long term functional, cognitive, and quality of life outcomes within the current paradigm of stroke care delivery in the US is not understood. Furthermore, a subset of $\mathrm{ICH}$ patients that would optimally benefit from transfer to or management at centers with HLOC, such as Comprehensive Stroke Centers (CSCs), has not been identified. Finally, the comparative effectiveness of treating $\mathrm{ICH}$ patients at higher-resourced centers has not been provided. The study "Efficient Resource Utilization for Patients with Intracerebral Hemorrhage (EnRICH)" has been designed and is being implemented to provide evidence to address these important issues.

\section{Rationale}

The American Heart Association / American Stroke Association guidelines for management of $\mathrm{ICH}$ were updated in 2015. These guidelines added a new Class I, level $\mathrm{B}$ evidence stating, "Initial monitoring and management of ICH patients should take place in an intensive care unit or dedicated stroke unit with physician and nursing neuroscience acute care expertise" [11]. The guidelines provide reference to three non-randomized studies as the basis for this evidence.
The first reference is made to a retrospective comparative analysis of $1038 \mathrm{ICH}$ patients admitted to a general (non-neurological) intensive care unit (ICU) and those admitted to a neurological ICU (NICU) [12]. The data were collected under Project Impact that began in 1996. The duration of data collection for patients included in this study is not clear; however, since the study was published in 2001 it is assumed that the 3 years of included data are between 1996 and 2001. The study reported an odds ratio (95\% Confidence Interval [CI]) of 3.43 (1.657.60) for inpatient mortality among ICH patients admitted to a general ICU as compared to NICUs. The authors did acknowledge that limited data from NICUs (only two were included), and voluntary participation of hospitals in the project can lead to selection bias and lack of generalizability. However, it is also pertinent to note that analyses were done at the patient level, and clustering of patients within ICUs and NICUs was not accounted for.

The second reference is made to a cross-sectional analysis of data from 49 acute care hospitals in Alberta, Canada, including 18,142 patients with diagnoses of acute myocardial infarction, congestive heart failure, chronic obstructive pulmonary disease or stroke between April 1, 1998 and March 31, 1999 [13]. The analyses were conducted with the aim of evaluating the association between nurse education and skill, continuity of care, quality of the work environment, and 30-day all-cause mortality. The authors correctly identified certain limitations pertaining to the nature of administrative data. However, it is apparent that the patient population included in this study does not allow generalizability of the results to ICH patients. Diagnosisbased stratified analyses have not been presented, and the only reported metric for stroke patients (presumably including ischemic stroke patients) is a $1 \%$ difference in 30 -day mortality (15\% vs. $16 \%$ ) between patients discharged from low vs. high volume hospitals.

The third observational study is an analysis of the data from the Swedish Stroke Register between 2001 and 2005 [14]. It compares the risk of death, institutionalization, and dependency between 105,043 stroke patients managed at stroke units and those managed at other types of units. The authors report a benefit for ICH patients managed in stroke units in terms of mortality and dependence. However, the study does not describe the differences between stroke and other units (primary exposure in this case) in care parameters for stroke patients. More importantly, the wider generalizability of such findings from a homogenous health care system remain questionable.

It is clear that the evidence cited in the guidelines falls short in multiple domains. These studies were not conducted during the last decade and they include data from non-stroke and non-ICH patients. Furthermore, their generalizability is highly questionable - particularly to the current paradigm of stroke care delivery 
and stroke care certification of hospitals in the US. Finally, they largely address broad and short-term outcomes such as inpatient and 30-day mortality. These outcomes, though important administratively, may not be patient-centered.

More recent and contextually relevant evidence, evaluating the association between level of care and outcomes in ICH patients, does not clearly highlight the benefit of managing all $\mathrm{ICH}$ patients at a HLOC. Two analyses independently conducted at large CSCs showed that transferred patients had milder disease severity and did not significantly utilize more CSC specific treatment modalities $[9,15]$. However, these data are limited by lack of outcomes for patients who are not transferred to CSCs. A direct comparison between ICH Medicare beneficiaries treated at Primary Stroke Centers (PSC) and those treated at non-certified centers did reveal a reduction in 30-day mortality for PSC patients; however, there were no differences in 30-day readmission [16]. This analysis did not consider differences between CSCs and PSCs, lacked patient-centered outcomes, and excluded patients $<65$ years of age, which may constitute a considerable proportion of ICH patients. A relatively recent comparison of brain hemorrhage patients treated at CSCs vs. PSCs did not reveal any differences in 90-day mortality for ICH patients [17].

Furthermore, there are limited and conflicting data on the comparative effectiveness of ICH patient transfer for HLOC. A recent simulation-based study provided comparative effectiveness in terms of incremental cost effectiveness ratios of $\$ 47,431$ per Quality Adjusted Life Years (QALY) for transferring ICH patients to a NICU under a most favorable scenario. However, these estimates are about $93 \%$ to $700 \%$ higher for less favorable scenarios [18]. Reliance on probabilistic assumptions behind simulation models, and interpretation of willingness-to-pay thresholds remain significant limitations of such analyses. Other studies based on primary data have reported that cost effectiveness of transfer of $\mathrm{ICH}$ patients is not clearly demonstrable, and that an evidence-based triage algorithm for optimal selection of patients is warranted [19].

Based on the above discussion, there is enough equipoise for EnRICH, which has the following aims:

1. To examine the association between level of care (as defined by certification status of the hospital) and outcomes in ICH patients

2. To estimate the health economic impact of management of ICH patients at CSCs, as compared to PSCs and / or non-certified hospitals

3. To characterize a subset of $\mathrm{ICH}$ patients that optimally benefits from care provision and management at HLOC (such as CSCs)

\section{Methods / design}

\section{Study design and setting}

EnRICH is designed to be an observational, prospective, multisite cohort study. It will be simultaneously operationalized at five major hubs in the state of Texas under the auspices of the Lone Star Stroke (LSS) Research Consortium of Texas. The LSS Research Consortium is a collaborative stroke research effort supported by the Texas legislature. Its mission is to conduct patientcentered stroke research across the state of Texas, with a specific focus on involving communities that generally do not have access to research, by utilizing the hub and spoke infrastructure of participating sites. One of the specific goals of the LSS charter is to "Develop and disseminate evidence-based guidelines for safe, high-quality, and cost-effective stroke care in Texas". The LSS network provides an ideal infrastructure to fulfill the aims of the EnRICH study, and the EnRICH study directly supports the stipulated goal of the LSS consortium's charter. Each LSS hub is a large, academic stroke treatment center designated as a CSC in most cases. A hub has a network of multiple other spoke hospitals, which are connected to the hub in their functionality via traditional arrangements or telemedicine technology. The spokes have varying patterns of transferring ICH patients to the hub. Some spokes transfer most or all ICH patients, whereas others tend to manage $\mathrm{ICH}$ patients in-house. Other spokes have varying proportions of transfer / non-transfer ICH patients. The details of the network and participating sites are publically available [20]. This framework provides an opportunity to enroll $\mathrm{ICH}$ patients who directly present either to CSC or non-CSC hospitals, and are either transferred or not transferred for HLOC.

\section{Study population}

All male and female adult patients ( $\geq 18$ years), of all races and ethnicities are eligible to be enrolled in EnRICH if they have a radiologically confirmed $\mathrm{ICH}$ (usually requiring only a non-contrast head computed tomography (CT) scan) with an etiology such as hypertension, coagulopathy or cerebral amyloidosis. We initially excluded $\mathrm{ICH}$ patients presenting to an index hospital 24-h after symptom onset or last seen normal, however this exclusion criteria has been removed. In our experience, decisions made at non-CSC centers to transfer radiologically confirmed ICH patients to a higher level of care are not influenced by time lapse between onset of symptoms and presentation. Among the population of transferred patients, only those patients who transfer within $24 \mathrm{~h}$ of their initial presentation are enrolled. Although patients with intraventricular extension of an intracerebral hemorrhage are eligible, patients with a pure or primary intraventricular hemorrhage are excluded. These patients may benefit from ventricular drainage procedures along with neurological 
monitoring in CSCs or other larger centers. Similarly, patients with other forms of intracranial hemorrhages, such as subdural and subarachnoid, are excluded. Patients with secondary causes of intracerebral hemorrhage - such as neoplasm, arteriovenous malformation, cerebral aneurysm, or hemorrhagic transformation of ischemic stroke - are also excluded. Secondary causes of hemorrhage are determined based on diagnostic work-up during the course of hospitalization. Potentially eligible patients are screened daily upon admission. Patients with non-primary ICH are excluded. Patients with unclear etiology are not approached, but are monitored for their diagnostic work-up and are only approached if secondary causes of ICH are excluded. If diagnostic work-up determines a secondary etiology after enrollment, patients are removed from the study. In such cases patients / their care-givers and the institutional review board (IRB) is duly notified. Detailed screening and enrollment are being maintained that track every potential $\mathrm{ICH}$ patient presented at an enrolling site. An IRB approved protocol amendment allows us to also enroll eligible ICH patients who die in-hospital prior to being approached for consent.

\section{Study procedures}

Eligible ICH patients with radiological confirmation of a parenchymal hemorrhage are approached to consent during their hospitalization. EnRICH is currently approved by the University of Texas Health Science Center at Houston (UTHealth) Institutional Review Board (IRB) to obtain a verbal consent from either the patient or their legally authorized representative. Upon consent, several baseline assessments are completed with the patient or by proxy, and certain preliminary information about patients - including demographic, risk factors, and initial presentation variables - is captured in the study-specific, online, secure database. Information describing inpatient management, such as treatment intensity, length of stay, procedures, laboratory investigations, and diagnostic modalities, are also captured. After discharge from acute care, consented patients are followed at 30 and 90 days via phone calls to obtain information on functional, QOL, cognitive, resource utilization, and level of dependency outcomes. A schematic representation of patient flow and information collected for EnRICH at various study phases is presented in Fig. 1.

\section{IRB approvals and multisite implementation}

The University of Texas Health Science Center at Houston IRB is the IRB of Record. The project has been approved at various study sites via IRB reciprocity, and we aim to maintain single IRB review in compliance with the current regulatory trend. An electronic study master file has been designed and implemented to facilitate inter-site communication and centralized storage of essential study documents.

\section{Outcomes}

The 90-day functional status as assessed by modified Rankin Scale (mRS) is the primary outcome. Secondary outcomes include 30-day readmission and 30-day mortality. The outcome for economic analysis is the relative cost effectiveness of $\mathrm{ICH}$ patient management at varying levels of care (i.e. CSCs vs. non-CSC hospitals). Cost effectiveness ratios are comprised of Cost (as determined by total costs of inpatient treatment intensity, transfer status, and post-discharge resource utilization weighted by Medicare reimbursement amounts) and effectiveness (as obtained by QALYs determined by EQ-5D QOL information). The exploratory outcomes include assessment of patients' health utility as captured by Standard Gamble, cognitive outcome determined using mini Montreal Cognitive Assessment (MoCA), and change in patient dependency status.

\section{Statistical analysis}

The primary analytical aim of EnRICH is to compare 90-day functional outcomes between $\mathrm{ICH}$ patients treated at CSCs and those treated and non-CSC hospitals. We propose to conduct a shift analysis of the seven point $\mathrm{mRS}$ (0-6) utilizing proportional odds models. Baseline variables will be assessed for imbalance between the two groups, and statistically significant $(p<0.1)$ potential confounders will be included in the multivariable models. Clinically important variables that are known to predict outcome in ICH patients (such as age, presentation National Institutes of Health Stroke Scale (NIHSS), presentation Glasgow Coma Scale (GCS), systolic blood pressure, hematoma volume, hemorrhage location, and hematoma expansion) will be included in the multivariable model regardless of their statistical significance. Model building, variable selection, and assessment of the fit of the model will be conducted utilizing methodologies described in standard texts [21]. Further analyses will also be conducted using propensity score based methods [22]. This will allow for quantification of bias and sensitivity analyses to explore robustness of the estimates to un-measured confounding. Secondary analyses based on utility weighted mRS (UW - mRS) will also be performed to provide estimates of effect size for future trials [23]. We propose to conduct multivariable modified Poisson regression and survival analyses for assessing relative risk of 30-day readmission, and hazard ratio for 30-day mortality respectively. Differences in the median scores for quality of life will be analyzed using quantile regression methods. Day- 90 cost effectiveness analysis will be performed from payer's perspective using Medicare weight reimbursement rates. Long-term (1 Year) costs and outcomes will be modeled using Markov modeling. Sensitivity analyses will be conducted to determine the robustness of the incremental cost effectiveness ratio. Finally, receiver operating curve 


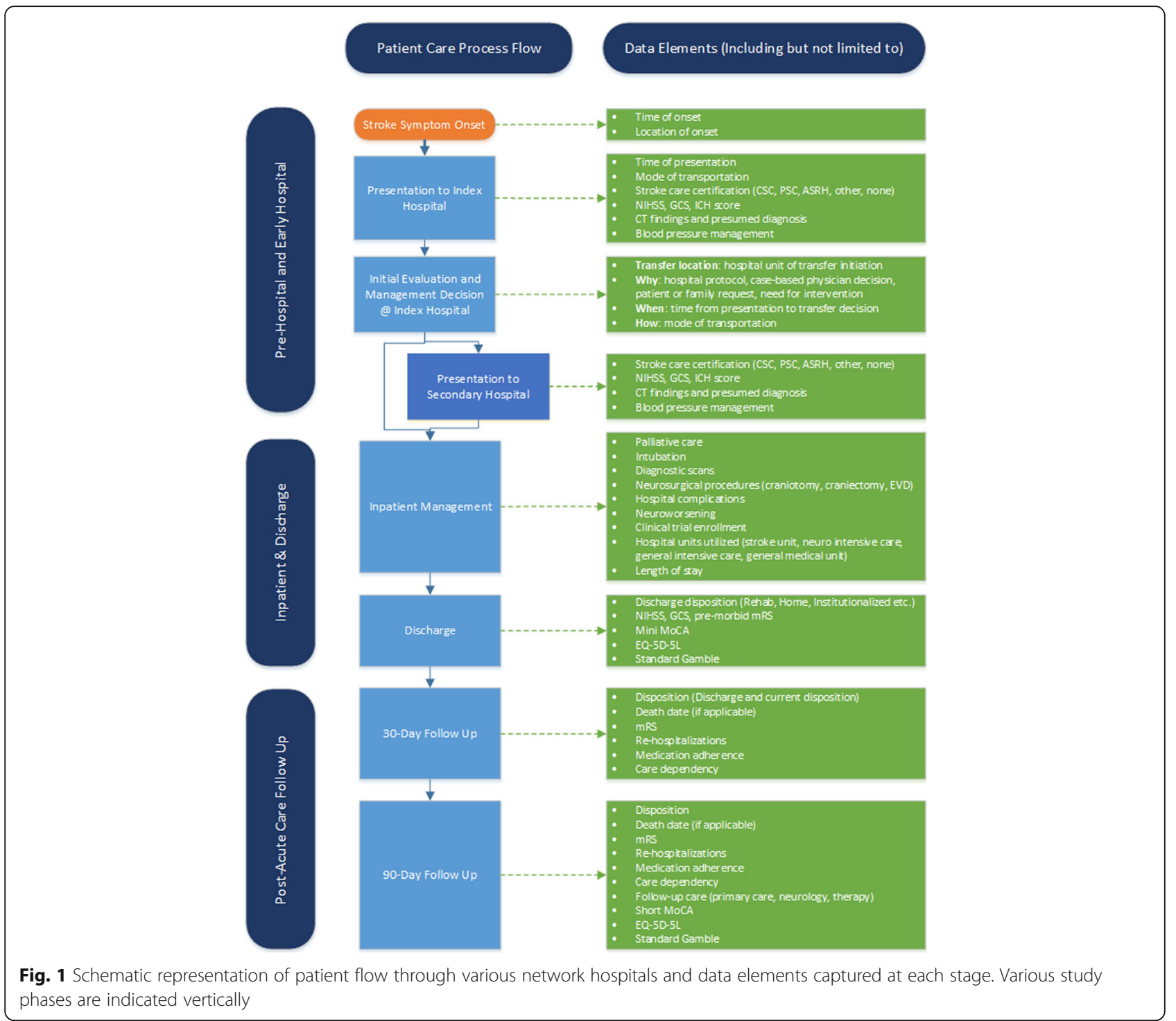

based predictive scores will be developed for $\mathrm{ICH}$ patients who are likely to benefit from care at CSCs. This will help identify a subset of $\mathrm{ICH}$ patients optimally benefiting from HLOC.

\section{Sample size and power}

The power and sample size calculations of the study have been conducted to satisfy the primary endpoint of 90-day mRS. We determined the 90-day distribution of $\mathrm{mRS}$ for ICH patients using published literature [24]. In addition, based on our prior work we estimate that approximately $60 \% \mathrm{ICH}$ patients are managed at CSCs [9]. Therefore using a ratio of 1.5 for CSC vs. Non-CSC patients, a total of 1110 patients are needed to achieve $80 \%$ power to detect a change in log odds ratio of 0.3 with the significance level of 0.05 for a two-sided test [25]. Factoring in an attrition rate of $20 \%$ we plan to enroll
1375 patients $(825$ CSC patients and 550 non-CSC patients) over the period of 2.5 years, such that all follow up is completed within 3 years of study duration.

\section{Progress}

Since initiation in September 2016, EnRICH has been operationalized at a total of nine hospitals in larger metropolitan areas of Houston, Austin, San Antonio, and Dallas.. Study start-up procedures are currently ongoing at two other LSS hubs. To-date, over 870 patients have been screened and 480 patients have been enrolled. The current loss to follow up rate for both the 30 and 90 -day time points is less than $5 \%$. Fig. 2 shows a flow diagram of the number and proportion of screened, approached, consented, and enrolled patients. Reasons for non-enrollment are also indicated. Since the approval and implementation of a verbal consent process in late 


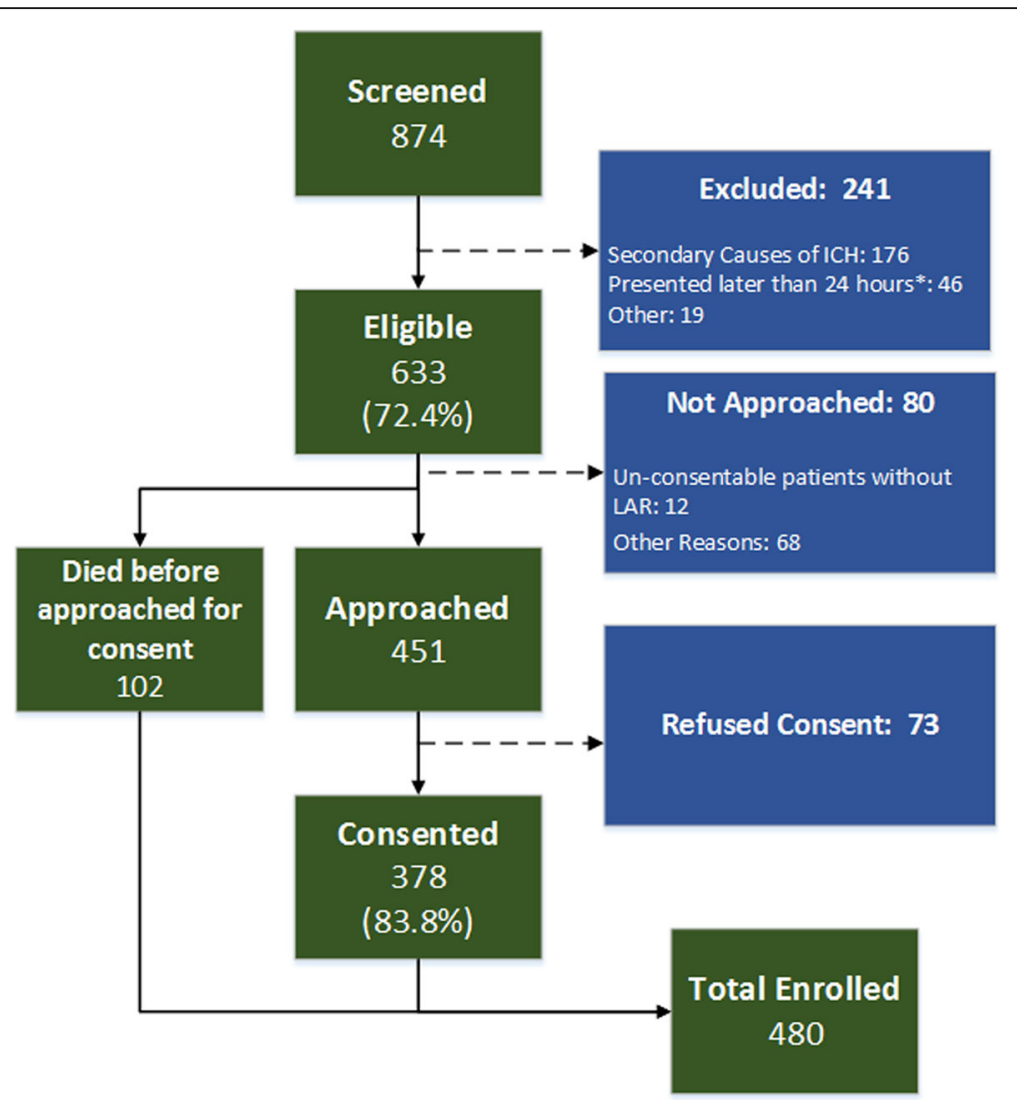

Fig. 2 Flow diagram for screening, eligibility, approach, and consent for current status of EnRICH (combined for all participating sites)

September 2016, the refusal rate for study participation has declined from $41.0 \%$ to $16.2 \%$.

\section{Discussion}

EnRICH is a statewide cohort of ICH patients that will answer important questions regarding regionalization of care. The rationale of EnRICH stems from the gravity of the disease, lack of definitive treatment modalities for $\mathrm{ICH}$ patients, and current practice patterns in the absence of class I evidence. Though it remains critically important to explore novel management strategies for $\mathrm{ICH}$ treatment, it is perhaps even more crucial to ensure that the resources within current stroke care delivery systems are optimized to provide maximal benefit for ICH patients. On one hand, the implementation of evidence-based management practices are important, but at the same time, non-evidence based practices are necessary to be evaluated and eventually de-implemented. Parameters for management of $\mathrm{ICH}$ patients at a given level of care lack clarity and specificity, resulting in undue strain on systems of care, with probably little to no impact on patientcentered outcomes. Synthesized evidence supporting national guidelines and certifications should provide generalizable content and need to be contextually relevant. EnRICH will provide much needed data relevant to the changing and future paradigm of stroke care delivery in the US, in which an increasing number of stroke care facilities strive to achieve a certification status [26].

It is likely that decisions to transfer ICH patients for HLOC is an interplay of multiple patient, clinical, caregiver, physician, policy, and resource factors; with significant facilities-wide and regional variation. Recognizing the array of stakeholders in the transfer process, we conducted multiple brainstorming and focused group discussions with clinical trial design experts, analysts, stroke neurologists, neuro-intensivists, emergency care physicians, hospital administrators, members of committee for protection of human subjects, and patients and their care givers. All agreed that a trial in which patients were randomized to either stay at a certain hospital, or be transferred to a different one, was not feasible. Furthermore, there is a dearth of evidence that would establish criteria for transfer of brain hemorrhage patients to a higher level of care. The current guidelines provide extremely broad and non-precise parameters. We do hypothesize that transfer is beneficial for a certain subset of ICH patients, and believe that our work will help establish these parameters more precisely. Given this information, we continue to assess the feasibility of a step-wedge randomization design for the next phase of the study. The data from EnRICH will 
help us to design such a randomized trial. Therefore, despite the limitation of observational data, EnRICH is best suited to provide evidence leading to a better understanding of the impact of the level of care on outcomes for ICH patients. The design is also conducive to implementation at multiple sites, particularly those with limited resources for stroke research.

The results of the EnRICH study will have important implications for public policy and care provision, and may support evidence-based adaptation by healthcare systems. The current practice of indiscriminate patient transfer is not sustainable and is unlikely to translate into optimal societal benefit, particularly in non-urban populations with limited access to care. Economic analyses of EnRICH data will further inform rational decisions regarding the allocation of limited resources, and analyses of ICH patient outcomes - including patient quality of life will provide direction to agencies responsible for hospital accreditation as they formulate standards and guidelines for care of ICH patients.

\begin{abstract}
Abbreviations
Cl: Confidence interval; CSC: Comprehensive stroke center; EQ-5D: EuroQol - 5 Dimensions; GCS: Glasgow coma scale; HLOC: Higher level of care; ICH: Intracerebral Hemorrhage; IRB: Institutional review board; LSS: Lone star stroke; MoCA: Montreal cognitive assessment; mRS: Modified rankin scale; NICU: Neurological intensive care unit; NIHSS: National institutes of health stroke scale; PSC: Primary stroke center; QALY: Quality-adjusted life years; QOL: Quality of life; US: United States; UW-mRS: Utility weighted modified rankin scale
\end{abstract}

\begin{abstract}
Acknowledgments
We acknowledge contributions of Audrey 'Sarah' Cohen toward operationalization and initial acquisition of data. We acknowledge the roles of the Memorial Hermann Hospital System and Seton Healthcare Family in acquisition of data and study oversight. We acknowledge the support provided by the Biostatistics/ Epidemiology/ Research Design (BERD) component of the Center for Clinical and Translational Sciences (CCTS) for this project. CCTS is mainly funded by a grant (UL1 TR000371) from the National Center for Advancing Translational Sciences (NCATS), awarded to University of Texas Health Science Center at Houston. The content is solely the responsibility of the authors and does not necessarily represent the official views of the NCATS.
\end{abstract}

\section{Funding}

EnRICH is funded by the Texas State Legislature via the Lone Star Stroke Research Consortium. Neither the Texas State Legislature nor the Lone Star Stroke Research Consortium influenced study design, data collection and analysis, data interpretation or writing of this manuscript. The contents of this manuscript are solely the responsibility of the authors and do not necessarily represent the official views of the State of Texas.

\section{Availability of data and materials}

Not applicable.

\section{Authors' contributions}

FV conceived the study design and methods, is responsible for analysis and interpretation of study data, drafted this manuscript, gave final approval for publication, and is accountable for all aspects of the work. EM, AB, JM made contributions to the acquisition of data and study design. CB, TCW, JT, CM, LM, SW and SS substantially contributed to the conception and design. RB, WA and GG made substantial contributions to the acquisition of data. All authors read and approved the final manuscript.

\section{Ethics approval and consent to participate}

The University of Texas Health Science Center at Houston IRB (FWA \#00000667) issued approval to conduct this study. Approvals from hospital research committees and/or leadership were obtained as required from participating hospitals. This study is conducted in accordance with the Declaration of Helsinki and applicable Federal regulations. Informed consent to participate in this research was obtained from all enrolled patients or their legally authorized representatives.

\section{Consent for publication}

Not applicable.

\section{Competing interests}

The authors declare that they have no competing interests.

\section{Publisher's Note}

Springer Nature remains neutral with regard to jurisdictional claims in published maps and institutional affiliations.

\section{Author details}

${ }^{1}$ Department of Neurology and the Institute for Stroke and Cerebrovascular Disease, McGovern Medical School, University of Texas - Health, Houston, TX, USA. ${ }^{2}$ Department of Management, Policy, and Community Health, School of Public Health, University of Texas Health Science Center at Houston, Houston, TX, USA. ${ }^{3}$ Center for Clinical Research and Evidence Based Medicine at McGovern Medical School, University of Texas Health Science Center at Houston, Houston, TX, USA. ${ }^{4}$ Department of Neurosurgery, McGovern Medical School, University of Texas Health Science Center at Houston, Houston, TX, USA. ${ }^{5}$ Department of Neurology, Dell Medical School, The University of Texas at Austin, Austin, TX, USA.

Received: 26 May 2017 Accepted: 12 March 2018

Published online: 21 March 2018

\section{References}

1. Krishnamurthi RV, Moran AE, Forouzanfar MH, Bennett DA, Mensah GA, Lawes CM, et al. The global burden of hemorrhagic stroke: a summary of findings from the GBD 2010 study. Glob Heart. 2014;9(1):101-6. https://doi. org/10.1016/j.gheart.2014.01.003. Epub 2014/11/30 PubMed PMID: 25432119

2. Hansen BM, Nilsson OG, Anderson H, Norrving B, Saveland H, Lindgren A. Long term (13 years) prognosis after primary intracerebral haemorrhage: a prospective population based study of long term mortality, prognostic factors and causes of death. J Neurol Neurosurg Psychiatry. 2013;84(10): 1150-5. https://doi.org/10.1136/jnnp-2013-305200. PubMed PMID: 23715913

3. van Asch CJ, Luitse MJ, Rinkel GJ, van der Tweel I, Algra A, Klijn CJ. Incidence, case fatality, and functional outcome of intracerebral haemorrhage over time, according to age, sex, and ethnic origin: a systematic review and meta-analysis. Lancet Neurol 2010;9(2):167-176. . doi: https://doi.org/10.1016/s1474-4422(09)70340-0. Epub 2010/01/09 PubMed PMID: 20056489.

4. Christensen MC, Mayer S, Ferran JM. Quality of life after intracerebral hemorrhage: results of the factor seven for acute hemorrhagic stroke (FAST) trial. Stroke. 2009;40(5):1677-82. https://doi.org/10.1161/strokeaha.108. 538967. Epub 2009/03/07 PubMed PMID: 19265046

5. Thabet AM, Kottapally M, Hemphill JC 3rd. Management of intracerebral hemorrhage. Handb Clin Neurol. 2017;140:177-94. https://doi.org/10.1016/ b978-0-444-63600-3.00011-8. Epub 2017/02/12 PubMed PMID: 28187799

6. Cooper D, Jauch E, Flaherty ML. Critical pathways for the management of stroke and intracerebral hemorrhage: a survey of US hospitals. Crit Pathw Cardiol. 2007;6(1):18-23. https://doi.org/10.1097/01.hpc.0000256146.81644.59. PubMed PMID: 17667882

7. Boulouis G, Morotti A, Goldstein JN, Charidimou A. Intensive blood pressure lowering in patients with acute intracerebral haemorrhage: clinical outcomes and haemorrhage expansion. Systematic review and meta-analysis of randomised trials. J Neurol Neurosurg Psychiatry. 2017;88(4):339-45. https://doi. org/10.1136/jnnp-2016-315346. Epub 2017/02/20 PubMed PMID: 28214798

8. Yang C-D, Chen Y-W, Wu H-C. Meta-analysis of randomized studies of surgery for supratentorial intracerebral hemorrhage. Formosan J Surg. 2014; 47(3):90-8.

9. Nguyen C, Mir O, Vahidy F, Wu TC, Albright K, Boehme A, et al. Resource utilization for patients with Intracerebral hemorrhage transferred to a 
comprehensive stroke center. J Stroke Cerebrovasc Dis. 2015;24(12):2866-74. https://doi.org/10.1016/j.jstrokecerebrovasdis.2015.08.023. PubMed PMID: 26460244; PubMed Central PMCID: PMCPMC4688147

10. Vahidy F, Albright K, Donnelly JP, Shapshak AH, Savitz SI. Abstract WMP31: National Trends in Transfer of Patients With Intracerebral Hemorrhage to Teaching Hospitals. Am Heart Assoc; 2016.

11. Hemphill JC 3rd, Greenberg SM, Anderson CS, Becker K, Bendok BR, Cushman M, et al. Guidelines for the Management of Spontaneous Intracerebral Hemorrhage: a guideline for healthcare professionals from the American Heart Association/American Stroke Association. Stroke. 2015;46(7):2032-60. https://doi. org/10.1161/STR.0000000000000069. PubMed PMID: 26022637

12. Diringer MN, Edwards DF. Admission to a neurologic/neurosurgical intensive care unit is associated with reduced mortality rate after intracerebral hemorrhage. Crit Care Med. 2001;29(3):635-40. Epub 2001/05/ 25. PubMed PMID: 11373434

13. Estabrooks CA, Midodzi WK, Cummings GG, Ricker KL, Giovannetti P. The impact of hospital nursing characteristics on 30-day mortality. Nurs Res. 2005;54(2):74-84. Epub 2005/03/22. PubMed PMID: 15778649

14. Terent A, Asplund K, Farahmand B, Henriksson KM, Norrving B, Stegmayr B, et al. Stroke unit care revisited: who benefits the most? A cohort study of 105,043 patients in Riks-stroke, the Swedish stroke register. J Neurol Neurosurg Psychiatry. 2009;80(8):881-7. https://doi.org/10.1136/jnnp.2008. 169102. Epub 2009/04/01.PubMed PMID: 19332423

15. Kilbourn KJ, Killory BD, Fortunato G, Staff I, Sinisgalli S, Czap A, et al. Clinical characteristics and outcomes of patients with Intracerebral hemorrhage after Interhospital transfer to a designated stroke center. Conn Med. 2015; 79(6):335-41. Epub 2015/08/13. PubMed PMID: 26263713

16. Lichtman JH, Jones SB, Leifheit-Limson EC, Wang Y, Goldstein LB. 30-day mortality and readmission after hemorrhagic stroke among Medicare beneficiaries in joint commission primary stroke center-certified and noncertified hospitals. Stroke. 2011;42(12):3387-91.

17. McKinney JS, Cheng JQ, Rybinnik I, Kostis JB. Comprehensive stroke centers may be associated with improved survival in hemorrhagic stroke. J Am Heart Assoc. 2015;4(5):e001448.

18. Fletcher JJ, Kotagal V, Mammoser A, Peterson M, Morgenstern LB, Burke JF. Cost-effectiveness of transfers to centers with neurological intensive care units after intracerebral hemorrhage. Stroke. 2015:46(1):58-64. https://doi. org/10.1161/STROKEAHA.114.006653. PubMed PMID: 25477220; PubMed Central PMCID: PMC4276522

19. Nakagawa K, Galati A, Juarez DT. The excess cost of interisland transfer of intracerebral hemorrhage patients. Am J Emerg Med. 2015;33(4):512-5 https://doi.org/10.1016/j.ajem.2015.01.001. PubMed PMID: 25624077; PubMed Central PMCID: PMC4409479

20. Lone Star Stroke Consortium 2017. Available from: http://lonestarstroke.com/

21. Hosmer Jr DW, Lemeshow S, Sturdivant RX. Applied logistic regression. New York: Wiley; 2013.

22. Guo S, Fraser MW. Propensity score analysis. Los Angeles: Sage; 2014.

23. Broderick JP, Adeoye O, Elm J. Evolution of the modified Rankin scale and its use in future stroke trials. Stroke. 2017;48(7):2007-12.

24. Palm F, Henschke N, Wolf J, Zimmer K, Safer A, Schroder RJ, et al. Intracerebral haemorrhage in a population-based stroke registry (LuSSt): incidence, aetiology, functional outcome and mortality. J Neurol. 2013; 260(10):2541-50. https://doi.org/10.1007/s00415-013-7013-0. PubMed PMID: 23812642

25. Whitehead J. Sample size calculations for ordered categorical data. Stat Med. 1993;12(24):2257-71. PubMed PMID: 8134732

26. Song S, Saver J. Growth of regional acute stroke systems of care in the United States in the first decade of the 21st century. Stroke. 2012;43(7): 1975-8. https://doi.org/10.1161/STROKEAHA.112.657809. PubMed PMID: 22669404; PubMed Central PMCID: PMCPMC3413285

\section{Submit your next manuscript to BioMed Central and we will help you at every step:}

- We accept pre-submission inquiries

- Our selector tool helps you to find the most relevant journal

- We provide round the clock customer support

- Convenient online submission

- Thorough peer review

- Inclusion in PubMed and all major indexing services

- Maximum visibility for your research

Submit your manuscript at www.biomedcentral.com/submit

) Biomed Central 